Erratum

\title{
Erratum to "Development of Delivery Systems Enhances the Potency of Cell-Based HIV-1 Therapeutic Vaccine Candidates"
}

\author{
Amin Hadi $\mathbb{D}^{1},{ }^{1}$ Abbas Rastgoo $\left(\mathbb{D},{ }^{2}\right.$ Maryam Eskandarian $\mathbb{D}^{3},{ }^{3}$ Nooshin Haghighipour $\left(\mathbb{D},{ }^{4}\right.$ \\ and Azam Bolhassani ${ }^{5}{ }^{5}$
}

${ }^{1}$ Cellular and Molecular Research Center, Yasuj University of Medical Sciences, Yasuj, Iran

${ }^{2}$ School of Mechanical Engineering, University of Tehran, Tehran, Iran

${ }^{3}$ Department of Immunology, Tarbiat Modares University, Tehran, Iran

${ }^{4}$ National Cell Bank of Iran, Pasteur Institute of Iran, Tehran, Iran

${ }^{5}$ Department of Hepatitis and AIDs, Pasteur Institute of Iran, Tehran, Iran

Correspondence should be addressed to Nooshin Haghighipour; haghighipour@pasteur.ac.ir and Azam Bolhassani; a_bolhasani@pasteur.ac.ir

Received 16 June 2021; Accepted 16 June 2021; Published 7 July 2021

Copyright (c) 2021 Amin Hadi et al. This is an open access article distributed under the Creative Commons Attribution License, which permits unrestricted use, distribution, and reproduction in any medium, provided the original work is properly cited.

In the article titled "Development of Delivery Systems Enhances the Potency of Cell-Based HIV-1 Therapeutic Vaccine Candidates" [1], the contact details for author "Azam Bolhassani" were incorrect. The correct contact information is a_bolhasani@pasteur.ac.ir “a_bolhasani@pasteur.ac.ir.”

The error was introduced during the production process of the article, and Hindawi apologises for causing this error in the article.

\section{References}

[1] A. Hadi, A. Rastgoo, M. Eskandarian, N. Haghighipour, and A. Bolhassani, "Development of Delivery Systems Enhances the Potency of Cell-Based HIV-1 Therapeutic Vaccine Candidates," Journal of Immunology Research, vol. 2021, Article ID 5538348, 12 pages, 2021. 